\title{
GAMBARAN KEPUASAN PASIEN RAWAT JALAN DALAM MENERIMA PELAYANAN BPJS KESEHATAN DI PUSKESMAS BLAHBATUH I GIANYAR
}

\author{
I Gede Abdi Sarya Permana ${ }^{1}$, Komang Menik Sri Krisnawati ${ }^{2}$, Kadek Eka Swedarma ${ }^{3}$ \\ ${ }^{123}$ Program Studi Sarjana Keperawatan Dan Profesi Ners Fakultas Kedokteran Universitas Udayana \\ Alamat Korespondensi: abdisarya9@gmail.com
}

\begin{abstract}
Abstrak
Kesehatan merupakan kebutuhan dasar manusia untuk dapat hidup layak dan produktif, untuk itu diperlukan penyelenggara pelayanan kesehatan yaitu Jaminan BPJS Kesehatan yang selaras dengan tujuan untuk mengakses pelayanan kesehatan yang bermutu. Berbagai cara akan dilakukan setiap orang untuk mendapatkan pengobatan yang baik, salah satunya dengan berobat ke pelayanan kesehatan seperti rumah sakit maupun Puskesmas untuk memberikan pelayanan kesehatan yang bermutu agar tercipta kepuasan pasien. Tujuan penelitian untuk mengetahui kepuasan pasien rawat jalan peserta BPJS Kesehatan di Puskesmas Blahbatuh I Gianyar. Jenis penelitian ini adalah penelitian deskriptif pendekatan cross sectional. Sampel diambil dengan teknik purposive sampling yaitu 100 responden. Instrumen penelitian ini adalah kuesioner. Hasil penelitian dimensi tangible sebanyak 20 pasien (20\%) dalam kategori sangat memuaskan, 71 pasien (71 \%) dalam kategori memuaskan, dan 9 pasien (9\%) pada kategori kurang memuaskan. Dimensi reliability sangat memuaskan sebanyak 27 pasien $(27 \%)$ dan memuaskan sebanyak 73 pasien $(73 \%)$. Dimensi responsiveness pasien dengan sangat memuaskan sebanyak 27 pasien (27\%), memuaskan 67 pasien (67\%), dan kurang memuaskan 6 pasien $(6 \%)$. Dimensi assurance sangat memuaskan sebanyak 20 pasien (20\%) dan memuaskan sebanyak 80 pasien (80\%). Dimensi empathy sangat memuaskan sebanyak 21 pasien $(21 \%)$ dan memuaskan sebanyak 79 pasien $(79 \%)$. Dapat disimpulkan bahwa dominan responden dalam kategori memuaskan pada dimensi tangible, reliabilty, responsiveness, assurance, dan empathy.
\end{abstract}

Kata Kunci: BPJS Kesehatan, Kepuasan Pasien, Rawat Jalan

\begin{abstract}
Health is a basic human need to be able to live worthy and productive, so it needed to provide health services, namely health social services agency which is aligned with the goal to access quality health services. Each person will do the various ways to get a good treatment, included health services such as hospitals and health center to provide the quality of health service so it will lead to the patients satisfaction. Research Objective to know the patients satisfaction of health social services agency participants of outpatient service in health center of Blahbatuh I Gianyar. This research was kind of deskriptif with cross sectional approach. Sample taken by purposive sampling as many 84 respondents. Research instrument was questioner. The results of the tangible dimension study were 20 patients $(20 \%)$ in the very satisfying category, 71 patients $(71 \%)$ in the satisfying category, and 9 patients $(9 \%)$ in the unsatisfactory category. The reliability dimension was very satisfying because of 27 patients (27\%) and as many as 73 patients (73\%). The dimensions of patient responsiveness were very satisfying as many as 27 patients $(27 \%)$, satisfying 67 patients $(67 \%)$, and satisfying 6 patients $(6 \%)$. The assurance dimension is very satisfying as many as 20 patients $(20 \%)$ and satisfies as many as 80 patients $(80 \%)$. The empathy dimension is very satisfying as many as 21 patients (21\%) and satisfying as many as 79 patients (79\%). It can be concluded that the dominant respondents in the satisfying category are dimensions of tangible, reliability, responsiveness, assurance, and empathy.
\end{abstract}

Keywords: Health Social Services Agency, Patients Satisfaction, Outpatients 


\section{PENDAHULUAN}

Kesehatan adalah kebutuhan dasar manusia agar dapat hidup layak dan produktif (Suaib, 2015). Kesehatan masyarakat yang optimal merupakan cerminan dari pelayanan kesehatan yang maksimal. Pelayanan kesehatan merupakan salah satu hak mendasar masyarakat yang penyediaannya wajib diselenggarakan oleh pemerintah sebagaimana telah diamanatkan dalam Undang-Undang Dasar 1945 (Departemen Kesehatan Republik Indonesia, 2008).

Puskesmas merupakan salah satu penyedia layanan kesehatan yang paling dekat dengan masyarakat. Pelayanan puskesmas menyediakan layanan secara menyeluruh, termasuk upaya kuratif (pengobatan), preventif (pencegahan), promotif (peningkatan kesehatan), dan rehabilitatif (pemulihan) (Fery \& Makhfudli, 2009). Puskesmas terdiri dari dua jenis fungsi penyelenggara yaitu puskesmas sebagai rawat jalan dan puskesmas sebagai rawat inap. Hasbi (2012) menyatakan bahwa puskesmas lebih mengembangkan programnya untuk pasien rawat jalan sebagai fasilitas kesehatan tingkat pertama (FKTP) dengan observasi, diagnosis, dan pengobatan.

Pemberian pelayanan kesehatan akan mempengaruhi kualitas pelayanan. Kualitas pelayanan merupakan bentuk penilaian konsumen terhadap pelayanan yang diterima. Kualitas pelayanan menentukan kepuasan (Purcarea, Luliana, \& Consuela, 2013). Kementerian Kesehatan Republik Indonesia (2017) menyatakan bahwa pencapaian belum memuaskan pada kesiapan palayanan umum di puskesmas karena kurangnya fasilitas dan kurangnya tenaga kesehatan.

Kepuasan menjadi tolak ukur keberhasilan pemberian pelayanan kesehatan. Pohan (2007) menyatakan bahwa kepuasan pasien merupakan perasaan yang timbul akibat pelayanan yang diterima setelah membandingkan dengan apa yang diharapkan. Kepuasan pelayanan kesehatan menjadi harapan seluruh masyarakat sehingga diperlukan jaminan kesehatan yang memadai. WHO memberikan dukungan kepada negara yang berusaha memastikan seluruh masyarakat dapat menerima pelayanan kesehatan atau disebut dengan universal health covarege (WHO, 2012). Indonesia merupakan salah satu negara yang sedang dalam masa transisi mewujudkan universal health coverage atau Jaminan Kesehatan Nasional (JKN) (Dewan Jaminan Sosial Nasional, 2014).

Pemerintah mengeluarkan Undang-Undang Nomor 24 Tahun 2011 tentang Badan Penyelenggaraan Jaminan Sosial (BPJS) untuk mewujudkan universal health coverage dan mengembangkan jaminan kesehatan agar masyarakat dapat merasa puas terhadap pelayanan kesehatan (Dewan Jaminan Sosial Nasional, 2014; Syafrudin, Masyitoh, \& Rosynawaty 2014). Puskesmas merupakan ujung tombak pelayanan kesehatan tingkat primer. Hal ini menyebabkan Puskesmas menempati urutan teratas sebagai fasilitas kesehatan yang melayani pasien BPJS kesehatan (Fajarudiin, 2015). Peserta BPJS mengalami peningkatan setiap bulannya, sekitar 77 persen dari total seluruh penduduk Indonesia telah terdaftar sebagai peserta BPJS (Pebrianto \& Setiawan, 2018).

Peserta BPJS di Bali pada tahun 2016 telah mencapai angka 2.209.787 jiwa (Devhy, Yundari, Purwanti, \& Prihartaningsih, 2018). Kabupaten di Bali yang telah mencapai universal health coverage adalah Kabupaten Klungkung dan Badung (Mustofa, 
2019). Kabupaten Gianyar merupakan salah satu kabupaten di Bali yang kepesertaan BPJS kesehatan belum mencapai 100 persen yaitu hanya mencapai 75,26 \% (BPJS Kesehatan Klungkung, 2018).

$$
\text { Kepuasan peserta BPJS }
$$

kesehatan perlu diukur sebagai tolak ukur keberhasilan pemberian pelayanan kesehatan. Parasuraman, Zeithaml, \& Berry (1994) menyatakan teori Service Quality atau kualitas pelayanan (SERVQUAL), yang merupakan konsep teori yang meliputi lima dimensi yaitu tangible (bukti fisik), reliability (kehandalan), responsiveness (ketanggapan), assurance (jaminan), dan empathy (empati). Prihandhan, Hakim, \& Wirajaya (2018) menyatakan bahwa hasil survei kepuasan BPJS dari data BPJS divisi kesehatan regional tahun 2015 mendapatkan bahwa kepuasan peserta BPJS di Indonesia adalah 78,9\% dan di Bali yaitu 78,10\%. Kepuasan pasien BPJS kesehatan tidak luput dari fenomena yang dialami dalam menerima pelayanan.

Fenomena BPJS kesehatan yang terjadi di Indonesia, pada penelitian Pamella (2015) di Puskesmas Wilayah Utara Kota Kediri pada awal pelaksanaan BPJS kesehatan berkaitan dengan tidak sistematisnya waktu mengantri karena masih menggunakan fasilitas yang manual, hal ini mengakibatkan pasien mengeluh karena lamanya antrian dan sistematis data yang belum lengkap serta ada beberapa resep obat yang harus di beli di luar Puskesmas. Di Bali fenomena BPJS kesehatan yang dikeluhkan berupa rujukan BPJS kesehatan berbasis aplikasi, yang membuat Puskesmas menjadi kesulitan dalam sistem rujukan dengan keluhan dari beberapa pasien masalah jantung yang sudah intens berobat langsung di RSUD Klungkung dan harus dirujuk ke RS tipe $\mathrm{C}$ di Gianyar (Nusa Bali, 2018).

Hasil studi pendahuluan dilakukan di Puskesmas I Blahbatuh Gianyar yang merupakan puskesmas yang memiliki peserta BPJS terbanyak di wilayah Blahbatuh. Hasil tersebut mendapatkan jumlah kunjungan pasien rawat jalan pengguna BPJS tahun 2018 sebesar 12,487 pasien. Hasil wawancara yang dilakukan mengenai kendala dalam menerima pelayanan BPJS yaitu 4 dari 10 pasien mengatakan kurangnya kursi untuk mengantre dan juga 6 dari 10 pasien mengatakan parkiran Puskesmas sangat sempit sehingga kendala yang dialami bersifat tangible (bukti fisik). Berdasarkan hal tersebut, peneliti ingin mengetahui gambaran kepuasan pasien rawat jalan dalam menerima pelayanan BPJS kesehatan di Puskesmas Blahbatuh I Gianyar.

\section{METODE PENELITIAN}

Jenis penelitian ini yaitu penelitian deskriptif kuantitatif dengan pendekatan cross sectional. Penelitian dilakukan di Puskesmas Blahbatuh I Gianyar pada bulan Mei 2019 hingga Juni 2019.

Populasi penelitian ini yaitu pasien rawat jalan pengguna BPJS kesehatan di Puskesmas Blahbatuh I Gianyar pada tahun 2018 yaitu sekitar 12.487 pasien. Sampel dipilih dengan teknik non probability sample yaitu purposive sampling. Kriteria inklusi penelitian ini yaitu pasien rawat jalan dengan BPJS kesehatan yang bersedia menjadi responden, mampu membaca dan menulis, dan berusia $\geq 17$ tahun. Kriteria eksklusi penelitian ini yaitu pasien yang berkunjung tidak untuk berobat, pasien dengan gangguan jiwa dan mengalami penurunan kesadaran. Sampel dalam penelitian dihitung dengan rumus Slovin sehingga 
didapatkan jumlah sampel penelitian yaitu 100 responden.

Alat pengumpul data yang digunakan peneliti yaitu kuesioner SERVQUAL dari penelitian Triwardani (2017) yang terdiri dari 24 pernyataan yaitu dimensi tangible (bukti fisik), dimensi (keandalan), responsiveness (ketanggapan), assurance (jaminan), dan empathy (empati). Kuesioner ini telah dilakukan uji validitas dan reliabilitas oleh peneliti. Hasil uji validitas mendapatkan hasil $r$-hitung diantara 0,372 sampai 0,753 sehingga kuesioner ini dinyatakan valid. Hasil uji reliabilitas mendapatkan hasil cronbach's alpa $=0,750$ sehingga kuesioner ini dinyatakan reliabel.

Penelitian dilakukan setelah mendapat izin dari pihak terkait dan setelah mendapat keterangan laik etik dari Komisi Etika Penelitian FK Unud/RSUP Sanglah. Pengumpulan data dilakukan dengan memberikan kuesioner kepada responden. Pengisian kuesioner dilakukan kurang lebih 15 menit dan dibantu oleh peneliti dan dua orang asisten peneliti. Data yang telah terkumpul kemudian ditabulasi untuk dianalisis data.

Analisis data yang dilakukan yaitu analisis univariate terhadap variabel karakteristik responden dan tingkat kepuasan responden. Analisis data demografi dilakukan dengan melihat distribusi frekuensi. Sedangkan analisis kepuasan pasien dilakukan dengan menghitung skor gap.

\section{HASIL PENELITIAN}

Tabel 1 Data Demografi Pasien Rawat Jalan dalam Menerima Pelayanan BPJS Kesehatan di Puskesmas Blahbatuh I Gianyar

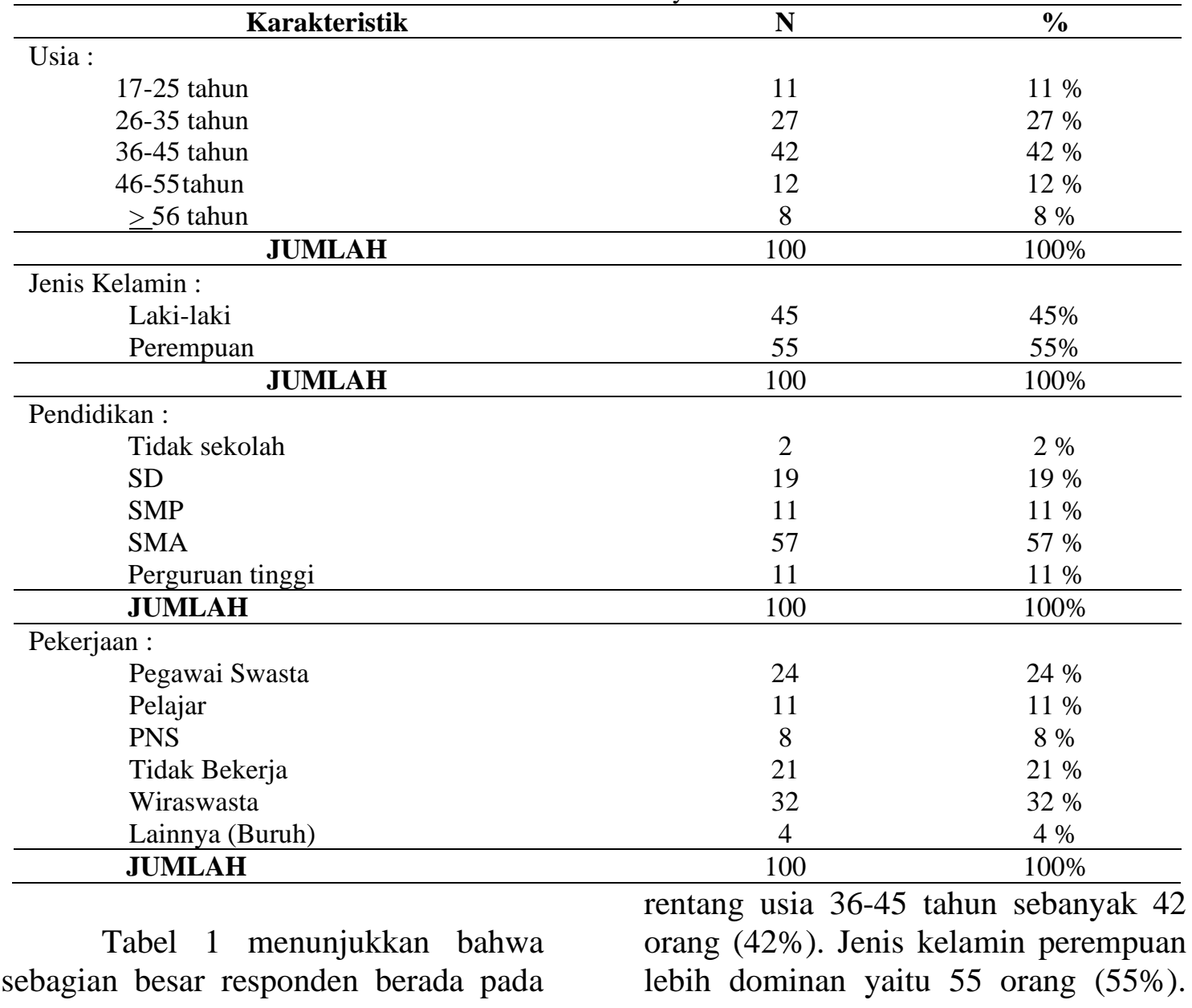


Pendidikan terakhir responden sebagian besar lulusan SMA yaitu 57 orang (57\%). Pekerjaan responden mayoritas

Tabel 2 Data Kepuasan Pasien Pasien Rawat Jalan dalam Menerima Pelayanan BPJS Kesehatan di Puskesmas Blahbatuh I Gianyar

\begin{tabular}{|c|c|c|c|c|c|c|c|c|}
\hline \multirow[t]{3}{*}{ Dimensi } & \multicolumn{6}{|c|}{ Perceived Service Quality } & \multicolumn{2}{|c|}{ Jumlah } \\
\hline & \multicolumn{2}{|c|}{ SM } & \multicolumn{2}{|c|}{$\mathbf{M}$} & \multicolumn{2}{|c|}{ KM } & & \\
\hline & $\mathbf{N}$ & $\%$ & $\mathbf{N}$ & $\%$ & $\mathbf{N}$ & $\%$ & $\mathbf{N}$ & $\%$ \\
\hline Tangible & 20 & 20 & 71 & 71 & 9 & 9 & 100 & 100 \\
\hline Reliability & 27 & 27 & 73 & 73 & - & - & 100 & 100 \\
\hline Responsiveness & 27 & 27 & 67 & 67 & 6 & 6 & 100 & 100 \\
\hline Assurance & 20 & 20 & 80 & 80 & - & - & 100 & 100 \\
\hline Empathy & 21 & 21 & 79 & 79 & - & - & 100 & 100 \\
\hline
\end{tabular}

Keterangan: SM (Sangat Memuaskan), M (Memuaskan), KM (Kurang Memuaskan)

Tabel 2 menunjukkan bahwa dimensi tangible dominan dalam kategori memuaskan sebanyak 71 responden $(71 \%)$. Dimensi reliability dominan dalam kategori memuaskan sebanyak 73 responden $(73 \%)$. Dimensi responsiveness dominan dalam kategori memuaskan sebanyak 67 responden (67 \%). Dimensi assurance dominan dalam kategori memuaskan sebanyak 80 responden (80\%). Dimensi empathy dominan dalam kategori memuaskan sebanyak 79 responden (79\%).

\section{PEMBAHASAN}

Hasil penelitian menunjukkan bahwa rentang usia responden dominan pada kelompok umur 36-45 tahun (dewasa akhir) sebanyak 42 responden (42\%). Hal ini karena dewasa akhir adalah individu yang mulai menunjukkan perhatiannya terhadap apa yang dihasilkan, keturunan, produkproduk, ide-ide, dan didominasi oleh pemuasan dan kesenangan diri sendiri saja (Desmita, 2012). Lumenta (1989) juga menyatakan bahwa umur produktif mempunyai tuntutan dan harapan lebih besar dibandingkan umur tua serta umumnya lebih agresif mencari informasi dan tidak menunjukkan sikap menyesuaikan diri.

Hasil penelitian menunjukkan jenis kelamin responden dominan pada jenis kelamin perempuan sebanyak 55 responden $(55 \%)$. Hal ini sejalan dengan penelitian Rangkuti (2006) yang sebagai wiraswasta yaitu 32 orang $(32 \%)$. menyatakan bahwa tingginya angka kesakitan pada perempuan daripada laki-laki menyebabkan perempuan membutuhkan pelayanan kesehatan yang lebih banyak. Gary (2003) juga menyatakan bahwa perempuan cenderung memiliki penilaian lebih terhadap fasilitas kesehatan dibandingkan laki- laki.

Hasil penelitian menunjukkan pendidikan responden dominan lulusan SMA sebanyak 57 responden (57\%). Hal ini didukung oleh penelitian dari Yulianti (2013) yang menyatakan bahwa semakin tinggi pendidikan akan semakin tinggi keinginan untuk memanfaatkan pengetahuan dan keterampilan, juga akan memiliki kecenderungan untuk melakukan tuntutan, juga harapan yang lebih tinggi. Rangkuti (2006) juga menyatakan bahwa pendidikan cenderung meningkatkan kesadaran akan status kesehatan dan konsekuensinya untuk menggunakan pelayanan kesehatan.

Hasil penelitian ini pada karakteristik pekerjaan dominan pada kelompok pekerjaan wiraswasta sebanyak 32 responden (32\%). Hal ini didukung dengan penelitian Yulianti (2013) bahwa pekerjaan wiraswasta merupakan profesi yang dikelola sendiri, sehingga tanpa ikatan waktu untuk menggunakan fasilitas kesehatan. 
Tangible dapat diartikan sebagai bukti fisik yaitu wujud yang dapat terlihat langsung dari penyedia pelayanan meliputi penampilan fisik, fasilitas, peralatan, sarana, informasi, dan petugas (Purcarea, Luliana, \& Consuela 2013). Hasil penelitian dimensi tangible dominan dalam kategori memuaskan sebanyak 71 responden (71 \%). Hal ini dibuktikan dengan skor pernyataan SERVQUAL dominan menyatakan puas yaitu pada kategori sangat memuaskan pada pernyataan petugas Puskesmas berpenampilan rapi dan profesional. Penelitian Komala (2013) menyatakan bahwa kepuasan pasien BPJS kesehatan terhadap pelayanan kesehatan di Puskesmas Kom Yos Sudarso Pontianak dari dimensi tangible adalah $78,53 \%$ yang dapat dikategorikan puas. Hasil memuaskan yang tinggi pada dimensi tangible juga didukung oleh penelitian Arianto (2017) yang menyatakan bahwa kepuasan pasien rawat jalan peserta BPJS kesehatan di Puskesmas Pandak II Bantul Yogyakarta dengan menyatakan puas berjumlah 71 responden $(84,5 \%)$.

Reliability mencakup dua hal pokok, yaitu konsistensi kerja (performance) dan kemampuan untuk dipercaya (dependability) (Purcarea, Luliana, \& Consuela 2013). Pada penelitian ini kepuasan pasien dimensi reliability dominan dalam kategori memuaskan sebanyak 73 responden ( 73 $\%)$. Hal ini diperkuat pada dimensi reliability memiliki skor pernyataan SERVQUAL dominan pada kategori sangat memuaskan dengan pernyataan Puskesmas memberikan pelayanan dengan segera. Arianto (2017) juga menyatakan bahwa kepuasan pasien rawat jalan peserta BPJS kesehatan di Puskesmas Pandak II Bantul Yogyakarta dengan menggunakan 84 responden dengan sebanyak 71 responden $(84,5 \%)$ dalam kategori memuaskan.
Responsiveness adalah kemampuan untuk membantu pelanggan dan meningkatkan ketepatan pelayanan untuk melayani konsumen dengan baik (Purcarea, Luliana, \& Consuela 2013). Pada penelitian ini kepuasan pasien dimensi responsiveness dominan dalam kategori memuaskan sebanyak 67 responden $(67 \%)$. Hal ini dibuktikan dengan skor pernyataan SERVQUAL dominan pada kategori sangat memuaskan pada pernyataan pihak Puskesmas menunjukkan kemauan untuk membantu pasien. Penelitian Arianto (2017) pada dimensi responsiveness, juga menyatakan bahwa kepuasan pasien rawat jalan peserta BPJS kesehatan di Puskesmas Pandak II Bantul Yogyakarta dengan pasien puas berjumlah 75 responden $(89,3 \%)$.

Assurance dapat diartikan sebagai jaminan kompetensi yang dimiliki sehingga membuat rasa aman, bebas resiko atau bahaya, kepastian yang mencakup pengetahuan, sikap, dan perilaku sehingga dapat menumbuhkan keyakinan atau kepercayaan pelanggan (Purcarea, Luliana, \& Consuela, 2013). Pada penelitian ini kepuasan pada dimensi assurance dominan dalam kategori memuaskan sebanyak 80 responden $(80 \%)$. Hal ini diperkuat dengan skor pernyataan SERVQUAL dominan pada kategori sangat memuaskan dengan pernyataan petugas Puskesmas selalu menunjukan sikap sopan dan santun. Komala (2013) menyatakan kepuasan pasien BPJS kesehatan terhadap pelayanan kesehatan di Puskesmas Kom Yos Sudarso Pontianak dari dimensi assurance yaitu $84,76 \%$ dikategorikan puas.

Empathy dapat diartikan sebagai empati adalah sifat dan kemampuan untuk memberikan perhatian penuh, rasa peduli, komunikasi yang baik, serta kemudahan untuk dihubungi (Purcarea, Luliana, \& Consuela 2013). Pada 
penelitian ini kepuasan pada dimensi empathy dominan dalam kategori memuaskan sebanyak 79 responden (79 $\%)$. Hal ini diperkuat dengan skor pernyataan SERVQUAL dominan pada kategori sangat memuaskan dengan pernyataan petugas Puskesmas mengutamakan kepentingan pasien dengan sepenuh hati. Komala (2013) yang menyatakan bahwa kepuasan pasien BPJS kesehatan terhadap pelayanan kesehatan di Puskesmas Kom Yos Sudarso Pontianak dengan hasil sebanyak $92 \%$ dapat dikategorikan memuaskan.

\section{KESIMPULAN DAN SARAN}

Penelitian ini menunjukkan bahwa kepuasan pasien rawat jalan pengguna BPJS kesehatan di Puskesmas Blahbatuh I Gianyar dari dimensi tangible dominan dalam kategori memuaskan, dari dimensi reliability dominan dalam kategori memuaskan, dari dimensi responsiveness dominan dalam kategori memuaskan, dari dimensi assurance dominan dalam kategori memuaskan, dan dari dimensi empathy juga dominan dalam kategori memuaskan.

Penelitian ini memiliki beberapa keterbatasan, sehingga peneliti menyarankan bagi peneliti selanjutnya untuk mengembangkan isi kuesioner agar mencakup proses administrasi dan alur rujukan dalam proses menerima pelayanan BPJS kesehatan. Puskesmas dan Pemerintah juga tetap mengevaluasi dan mengawasi pelaksanaan pelayanan dengan BPJS agar dapat meningkatkan pelayanan untuk mencapai kepuasan yang lebih baik.

\section{DAFTAR PUSTAKA}

Arianto, R.A. (2017). Gambaran Kepuasan Pasien Rawat Jalan Peserta BPJS Kesehatan di Puskesmas Pandak II Bantul Yogyakarta.[Skripsi]. Yogyakarta : Sekolah Tinggi Ilmu Kesehatan Jenderal Ahmad Yani.

BPJS Kesehatan Klungkung. (2018). Kepesertaan BPJS Kesehatan Kabupaten. Klungkung: BPJS Kesehatan Klungkung.

Departemen Kesehatan Republik Indonesia. (2008). Pedoman Pelaksanaan Jaminan Kesehatan masyrakat (Jamkesmas). Jakarta: Departemen Kesehatan Republik Indonesia.

Desmita.

(2012). Psikologi

Perkembangan. Bandung: PT Remaja Rosdakarya.

Devhy, P.L.N., Yundari, H.D.I.A.A., Purwanti, S.I., Prihartiningsih, D. (2018). Gambaran Kepuasan Pasien Rawat Jalan Peserta BPJS Kesehatan di Rumah Sakit Umum Daerah Sanjiwani di Kabupaten Gianyar Tahun 2018. Diunduh dari https://balimedikajurnal.com/ (Diakses 11 Maret 2019).

Dewan Jaminan Sosial Nasional . (2014). Paham Badan Penyelenggaran Jaminan Sosial Seri Buku Saku 2. Jakarta : CV Komunitas Pejaten Mediatama.

Fajaruddin, R.A. (2015). Kepuasan Masyarakat terhadap Pelayanan Kesehatan Pasien Pemegang Kartu Jaminan BPJS di Unit Pelayanan Teknis Kesehatan Puskesmas Kecamatan Bungkah Kabupaten Gresik. Diunduh dari https://jurnalmahasiswa.unesa.ac.id/ (Diakses 11 Maret 2019).

Fery \& Makhfudli. (2009). Kesehatan Komunitas: Teori dan Praktik dalam Keperawatan. Jakarta: Salemba Medika.

Gary, L.C. (2003). Key Patients Characteristic Influencing Customer Statisfiction in Community Health Centers. Dissertation. Philosophy of Arizona State University. Diunduh dari https://core.ac.uk/ (Diakses 2 April 2019).

Hasbi, H. (2012). Analisis Hubungan Persepsi Pasien Tentang Mutu Pelayanan Dengan Pemanfaatan Ulang Pelayanan Rawat Jalan Puskesmas Poncol Kota Semarang. Jurnal Kesehatan Masyarakat. Volume 1(2), 37-47.

Kementerian Kesehatan Republik Indonesia. (2017). Rencana Strategis Kementerian Kesehatan 2015-2019. Diunduh dari 
http://www.depkes.go.id/ (Diakses pada 10 Maret 2019).

Komala, A. (2015). Gambaran Tingkat Kepuasan Pasien Peserta BPJS Kesehatan terhadap Pelayanan Kesehatan di Puskesmas Kom Yos Sudarso Pontianak Tahun 2015.[Skripsi]. Pontianak : Universitas Tanjungpura.

Lumenta, B. (1989). Pelayanan Medis Citra, Konflik dan Harapan, Tinjauan Fenomena Sosial. Yogyakarta: Kanisius.

Mustofa, A. (2019). Pengguna BPJS di Bali 98,76 Persen, Angka Kepatuhan Bayar Iuran Rendah. Jawa Pos, 28 Maret 2019. Diunduh dari https://radarbali.jawapos.com/ (Diakses 11 Maret 2019).

Nusa Bali. (2018). Rujukan Berjenjang BPS Menuai Keluhan. Nusa Bali, 27 September 2018. Diunduh dari https://www.nusabali.com/ ( Diakses 11 Maret 2019).

Pamella, R. (2015). Kualitas Pelayanan BPJS Kesehatan di Puskesmas Kota Wilayah Utara Kota Kediri. Diunduh dari http://jurnalmahasiswa.unesa.ac.id/ (Diakses 17 Desember 2018).

Parasuraman, A., Zeithaml, A.V., \& Berry, L.L. (1994). Alternative Scale For Measuring Service Quality: A Comperative Assessment Based on Psychometric and Diagnostic Criteria. Journal of Retailing.Volume 70(3), Pp 201-230. Diunduh dari https://www.researchgate.net/ (Diakses pada 13 Maret 2019).

Pebrianto, F.,\& Setiawan, K. (2018). Peserta BPJS Kesehataan Capai 77 Persen Penduduk Indonesia. Tempo, 3 September $2018 . \quad$ Diunduh dari https://bisnis.tempo.co/ (Diakses 11 Maret 2019).

Pohan, I. S (2007). Jaminan Mutu Layanan Kesehatan : Dasar-Dasar Pengertian Dan Penerapan. Jakarta: EGC.

Prihandhan, I.G.A.A.S., Hakim, N.R., Wirajaya, I.G. (2018). Hubungan Kualitas Pelayanan terhadap Kepuasan Pasien BPJS Kesehatan di Puskesmas II Denpasar Selatan. Volume 1(2). Diunduh dari http://ejournal.binausadabali.ac.id/ (Diakses 11 Maret 2019).

Purcarea, V. L., Luliana,R.G., \& Consuela,M.P.(2013). The Assessment of Perceived Service Quality of Public Health Care Services in Romania Using the SERVQUAL Scale. Procedia Economics and Finance.Volume 6, pp.
573-585. Diunduh dari https://www.researchgate.net/ (Diakses pada 13 Maret 2019).

Rangkuti, F. (2006). Measuring Customer Satisfaction, Gramedia Pustaka Utama, Jakarta.

Suaib, (2015). Kualitas Pelayanan Kesehatan dengan Kepuasan Pasien BPJS di RSUD Kabupaten Luwu. FKM Universitas Hassanudin. Diunduh dari http://repository.unhas.ac.id (Diakses pada 18 Maret 2019).

Syafrudin, Masyitoh, S., \& Rosyanawaty, T. (2014). Manajemen Mutu Pelayanan Kesehatan Untuk Bidan. Jakarta: CV Trans Info Media.

Triwardani,Y. (2017). Faktor-Faktor yang Berhubungan dengan Kepuasan Pasien BPJS Pada Pelayanan di Puskesmas Pamulang.Skripsi. Universitas Islam Negeri Syarif Hidayatullah. Diunduh dari http://repository.uinjkt.ac.id/ (Diakses pada 10 Maret 2019).

World Health Organization (WHO). (2012). Universal Health Coverage . Diunduh dari http://www.who.int (Diakses pada 10 Maret 2019).

Yulianti. (2013). Analisis Kepuasan Unit Rawat Jalan Rumah Sakit Bhakti Yudha Depok Tahun 2012.Tesis. Fakultas Kesehatan Masyarakat Universitas Indonesia. Diunduh dari http://lib.ui.ac.id/ (Diakses 2 April 2019). 